\title{
A educação internacional e os resultados de cooperação Brasil-Alemanha na Unicentro
}

\author{
Margarida Gandara Rauen \\ Afonso Figueiredo Filho
}

Resumo: A silenciosa revolução da educação internacional demanda reformas que afetam todos os níveis da educação. No Brasil, enquanto enviamos nossos bolsistas ao exterior, também nos deparamos com os enormes desafios da oferta de educação pública "em casa." A avaliação da mobilidade internacional, portanto, muito além de qualquer rotina, implica o aspecto ético de sua relevância social, principalmente quanto ao desenvolvimento de ações de cooperação e o seu impacto nos cursos de graduação e pós-graduação. Nos estágios iniciais de internacionalização, o estabelecimento de parcerias internacionais por meio de projetos de pesquisa e mobilidade é uma estratégia eficiente, mas nem todo programa proporciona ações de cooperação. Neste trabalho, consideramos os resultados de uma abordagem construtivista na internacionalização do Curso de Engenharia Florestal da Universidade Estadual do Centro-Oeste (UNICENTRO) com o apoio das agências governamentais CAPES (Brasil) e DAAD (Alemanha).

Palavras-chave: Mobilidade. Interatividade. Cultura.

\section{International education and the results of Brasil-Germany cooperation at Unicentro}

Abstract: The silent revolution of international education requires a reform that affects all the levels of education. In Brazil, while we send students abroad, we also face enormous challenges regarding the public offer of education "at home". Therefore, the assessment of international mobility, beyond any routine, implies the ethical dimension of its social relevance, particularly regarding the development of cooperation actions and their impact upon undergraduate and graduate programs. The establishment of partnerships by means of research and mobility projects is an efficient strategy at the early stages of internationalization, but not every program allows for cooperation actions. This paper considers the results of a constructivist approach for the internationalization of UNICENTRO's Forestry Program with the support of the government agencies CAPES (Brazil) and DAAD (Germany).

Key words: Mobility. Interactivity. Culture. 


\section{Introdução}

O legado histórico de belicosidade entre tantos povos contribui para que o campo da educação internacional seja desafiador, apesar de sua notável expansão global e transcontinental. A preocupação com a melhoria da qualidade de convívio tornou-se dramática após as grandes guerras mundiais, motivando a Declaração Universal do Direitos Humanos, realização tardia, considerando-se as demais chacinas empreendidas em nome do desenvolvimentismo extrativista e suas ocupações arrasadoras para milhões de pessoas das comunidades nativas de nosso planeta. Numa fala em mesa redonda com Edgar Morin, na Universidade de Brasília, em 1999, o índio Marcos Terena, piloto de aviões, relatou a quantidade de relógios em contagem regressiva para os 500 anos do Brasil, em todas as cidades por onde passava. Numa crítica ao provável término de toda a euforia logo após o dia 22 de abril do ano 2000, afirmou:

Queremos lembrar que, quando Cabral aqui chegou, nós éramos quase mil povos. Hoje somos apenas 200 povos. [...] muitos brasileiros, incluindo estudantes e professores, não sabem que existem 200 povos indígenas no Brasil e 180 línguas faladas. [...] agora, olhamos para trás e vemos que quatro milhões de índios morreram e mais de 700 povos desapareceram (TERENA apud MORIN, 2010, p. 17).

Dos celtas aos africanos e aos povos da Ásia, da Oceania e das Américas, ninguém escapou dos processos de escravização, espoliação, apagamento cultural e destruição ambiental. No Brasil, onde se trabalha pelo Carnaval o ano inteiro, a mais recente contagem regressiva foi a da Olimpiada (2016). Mas em outros países, também se antecipam eventos de massa, sem atenção substancial ao impacto da enorme pegada de carbono decorrente das emissões do transporte aéreo, do consumo de energia e infra-estrutura demandados pela programação e acomodações nas cidades sede. A nossa posição histórica em relação às temáticas da solidariedade e do meio ambiente já implica o constrangimento desses dilemas éticos, os quais nenhuma retórica ameniza. Estamos cientes, também, do desafio epistemológico implícito nas políticas de sustentabilidade. Edgard Morin enfatiza o círculo vicioso da criação de novos tipos de dominação toda vez que se tenta eliminar um poder e o problema de não termos as soluções para criar uma nova sociedade:

[...] temos unicamente aspirações. Mas as aspirações também são problemáticas; a fórmula francesa de Liberdade, Igualdade e Fraternidade é muito bonita e tem a sua verdade. Entretanto, as três noções complementares estão em antagonismo, porque a liberdade, sozinha, 
mata tanto a igualdade como a fraternidade. Se a igualdade se impõe, mata a liberdade sem fazer a fraternidade [...]. Talvez, como pessoa, me considero não um vendedor de esperança, mas um vendedor de resistência, nada mais (MORIN, 2010, p. 38).

Uma grande questão da educação internacional, portanto, é rever a própria noção de resistência, evitando instaurar novas formas de dominação e minimizando as dicotomias de cultura/margem, vencedor / derrotado, defesa / combate, cuja manifestação é clara, entre muitas manifestações culturais, na arte engajada fora dos palcos e/ou espaços cênicos convencionais da segunda metade do século XX: Tolstoy e a Revolução Russa de 1917, conquistas de espaço em contexto de pós-colonização no Kenya dos anos 70, dilemas de refugiados na Tailândia, xenofobia e racismo nos Estados Unidos, trabalhos do Exército Vermelho da China, as reivindicações do Greenpeace pela natureza, o teatro de Augusto Boal $(1975 ; 1996)$ e as demonstrações de rua contra a heteronormatividade, entre outros temas de performances (COHEN-CRUZ, 1998). $\mathrm{O}$ ativismo, nas artes, se intensificou, na América Latina, com a liberdade de expressão, seja direcionado para a criação e a defesa de direitos humanos, nas intervenções urbanas de protesto e denúncia (Movimento Occupy), na ação direta e nas reivindicações de novos direitos políticos, com grande ênfase nas agendas da violência e do meio ambiente. Ao abordar o ativismo em artes, Richard Schechner observa que

A performance intercultural precisa ser estudada junto com a globalização porque ela surge como reações e, em alguns casos, como protestos contra um mundo crescentemente integrado. Ambas globalização e performance intercultural têm antecedentes históricos. A globalização, no colonialismo e no imperialismo; a performance intercultural, enquanto resultado do 'contato' entre os povos do mundo. Claramente, esses fenômenos em si estão ligados. (Nossa tradução de SCHECHNER, 2002, p. 226).

Exemplos ipressionantes de performance intercultural têm sido realizados por meio da Internet, seja no movimento "Occupy", em reivindicações na Turquia ou num Brasil bem disposto a interferir na política nacional, desde 2013. Longe das diferenças ideológicas que levaram Alexander Soljenitsin (falecido em 2008) e Prêmio Nobel de Literatura (1970) a passar de consciência da União Soviética (URSS) a crítico do liberalismo ocidental, ou diante do continuado embate entre as posições democrata e republicana nos Estados Unidos, e das outras tantas fragmentações políticas em cada país do mundo, a educação no seu mais amplo sentido, seja local ou internacional, é influenciada por diferentes 
práticas culturais de resistência, associadas a subjetividades, questões identitárias e modos específicos de interatividade. A antropofagia, grande símbolo do modernismo brasileiro, articulada em Macunaíma, de Mário de Andrade), permanece uma referência de sistemas de domínio, nos quais o embate de identidades sempre leva ao predomínio de uma classe. ${ }^{1}$ Outra prática de resistência é observada por Muniz Sodré, quando comenta a capoeira:

[...] o mestre capoeirista negro não ensina a seu discípulo - ao menos da maneira como a pedagogia ocidental entende o verbo ensinar, ou seja, o mestre não verbaliza nem conceitua seu saber para doá-lo metódicamente ao aluno. [...] A capoeira negra é um jogo sem leis - logo, sem método - para que nada novo instante seja preenchido por um novo gesto. O golpe eficaz tem de ser inesperado. Embora o repertório gestual seja finito, sua combinatória é absolutamente aberta. O capoeirista, senhor de seu corpo, improvisa sempre e, como o artista, cria. [... pode] adotar, em questão de segundos, uma atitude nova (SODRÉ, 2005, p. 160).

A dinâmica de defesa da capoeira ilustra uma prática antagônica aos parâmetros usuais de ensino, mas permance atada à idéia de embate. Enquanto reconhecemos a importância das culturas de resistência, vislumbrar a educação internacional requer transcender as lutas, as dicotomias de opressor e oprimido, bem como as políticas de esquerda e direita, ainda frequentes no imaginário das pessoas. O próprio termo globalização costuma desencadear conotações preocupantes no campo latino americano de educação porque potencializa os traumas do imperialismo, das sociedades colonizadas, e das relações econônimas e manipulação das pessoas no capitalismo.

É indispensável, no entanto, manter as relações econômicas e de poder em foco, sobretudo quanto aos temas de custo e benefício, percebendo-se que o compromisso com a educação pública é enfatizado por pesquisadores da área de educação:

Educação democrática implica expansão da cobertura, justiça social, qualidade científica e relevância social para todos. São exigências éticas e políticas que se requerem da educação pública, além de técnicas e científicas, pois são essenciais à construção de sujeitos sociais, à consolidação da sociedade democrática e dos processos de inclusão socioeconômica (DIAS SOBRINHO, 2013, p. 115).

1 Vide estudo de Renato Pompeu (1986) sobre os conceitos de constelação e sistema na dialética materialista, aplicados à feijoada como metáfora das diferenças de classe. 
A questão do acesso tem sido incansavelmente problematizada por nossos dirigentes universitários. $\mathrm{O}$ fato de que $73,69 \%$ das matrículas em cursos superiores não estão nas instituições sem fins lucrativos, segundo dados MEC-INEP, sugere o quão longe estamos de uma oferta quantitativamente justa de vagas (SANTOS et al., 2013). Neste cenário, o investimento em bolsas internacionais para universitários do sistema público pode ser considerado um avanço em termos de democratização.

A busca por inclusão socioeconômica fatalmente nos levaria a políticas de fortalecimento da educação focadas na interatividade internacional e, com isso, segue o questionamento de seu custo-benefício e configuram-se os desafios de avaliação abordados neste trabalho. Na primeira parte, revisamos possíveis indicadores pertinentes a educação internacional e problematizamos abordagens identificadas em programas de fomento, destacando a positivista e a construtivista. Na segunda parte, aplicamos esse referencial a um caso de internacionalização na UNICENTRO, uma instituição pública que atende cerca de 13 mil alunos em seus campi nas cidades de Irati e Guarapuava, no Parana.

\section{A avaliação da mobilidade internacional: em busca de indicadores}

Félix Guattari, ao iniciar o livro Caosmose, com primeira edição publicada em 1992 e contendo pesquisa apresentada em maio de 1990, no Colégio Internacional de Estudos Filosóficos Transdisciplinares, no Rio de Janeiro, refere-se aos grandes movimentos de subjetivação e afirma que "[...] não tendem necessariamente para um sentido emancipador" (GUATTARI, 2012, p. 12). Questiona, ainda: "Como [...] as populações da Europa Central e dos países do Leste superarão a amarga decepção que o Oeste capitalista lhes reservou até o presente?" (p. 13). Idos mais de 20 anos, desde as provocações de Caosmose, encontramos uma resposta possível a essa pergunta no programa Erasmus Mundus. Falecido em 1992, Guattari não viveu para conhecer a mais ousada tentativa de aproximação entre os países europeus, cujas políticas de internacionalização tomaram força em 1999, com a Declaração de Bolonha e o programa Erasmus Mundus. O caráter emancipatório do programa, pelo menos em relação às fronteiras políticas e culturais, se evidenciou na sua implementação (ou silenciosa revolução) por meio das ações de cooperação voltadas ao repensar das estruturas curriculares, à criação de alternativas pedagógicas e à adequação dos regulamentos de reconhecimento de estudos e validação de diplomas, assuntos cuja complexidade já foi abordada em nosso meio acadêmico (LIMA; AZEVEDO; CATANI, 2008). 
No Brasil, as transformações na universidade se intensificaram com os novos programas de mobilidade internacional implantados, na última década, por meio da CAPES e do CNPq em parceria com a Alemanha, a Bélgica, o Canada, a Espanha, a França, Portugal, os Estados Unidos e o Reino Unido. Finalmente, em 2011, o grande montante de recursos do Programa Ciência Sem Fronteiras tornou urgente a adequação institucional para incentivar, acolher e reconhecer estudos que emergiram como fabulosas oportunidades de sofisticação da qualidade da educação superior por meio da experiência internacional.

A abordagem acadêmica da internacionalização está dividida entre os avanços na formação de uma força de trabalho competitiva e a dimensão humana. No campo da Economia, destaca-se o potencial das carreiras cosmopolitas e a evolução dos mercados globais competitivos, com a inserção mundial de patentes e produtos. Allan Päll, coordenador da União Européia de Estudantes no biênio 2010-2012, em depoimento publicado por ocasião da Conferência Anual da European Association of International Education (EAIE - Associação Européia de Educação Internacional) em Dublin, defende a integração eficiente de inúmeras ferramentas digitais e eletrônicas para implementar currículos individuais, naquilo que ele denomina, a "[...] a emergência do aprendiz autônomo" (nossa tradução de PÄLL, 2012, p. 29) e no sentido de abolir os diplomas: "Os empregadores de todos os tipos estão recrutando constantemente. Precisam minimizar o tempo de contratação, mas o foco nos diplomas dos candidatos quando se avalia a quem contratar torna-se, progressivamente, a opção errada" (p. 30).

A mobilidade internacional no ensino superior além desses novos embates entre a razão mercadológica e a academia, requer atenção à complexidade psicossocial implicada em enviar pessoas ao exterior, retirando-as de um contexto cultural e reposicionando-as, abruptamente, em outro. Mesmo quando foi minimizada a barreira do idioma, a relocalização cultural inspira percalços. Da necessidade de avaliação em processos de mobilidade internacional, surgiram as boas práticas, difundidas por um Forum que integra cerca de 300 representantes de universidades de diversos países, consórcios e instituições prestadoras de serviço ao setor educacional.

O website do Forum of Education Abroad, cujos membros institucionais incluem faculdades e universidades norte-americanas, assim como instituições, agências e fundações de outros países, oferece diversos recursos, entre os quais, publicações padrões de boas práticas para a educação no exterior (FÓRUM SOBRE EDUCAÇÃO NO EXTERIOR, 2015). Os padrões tornaram-se referência para assessorias de educação internacional, contribuindo para o planejamento e o acompanhamento qualitativo nos programas de mobilidade e intercâmbio, 
principalmente quanto aos aspectos de acessibilidade, transparência e avaliação contínua. Nesse sentido, a elaboração um plano de chamadas com critérios transparentes de inscrição, seleção e "placement" [aceite na instituição de destino], o amparo à mobilidade por meio de regulamentação pertinente ao reconhecimento de estudos e/ou estágios, a orientação na composição do plano de estudos viabilizada na flexibilização curricular, a orientação pré-partida, as mediações com o provedor de estudos no exterior, o acompanhamento durante a estadia no exterior e no regresso à instituição de origem são procedimentos indispensáveis na oferta de um programa, culminando com as adequações para o cumprimento da legislação em cada país, seja por meio de acordos acadêmicos de cooperação ou de práticas diplomáticas. Entende-se que não existe um modelo único e nenhum programa deva ser considerado perfeito, embora o princípio geral de educação no exterior ${ }^{2}$ seja proporcionar o desenvolvimento de lideranças globais, respeitando-se um compromisso ético. O modelo da parceria bilateral, no entanto, é recomendado como um dos mais eficientes para a implementação de ações internacionais, fortalecendo-se quando articulado em redes de coperação e em programas de fomento governamental e/ou privados. ${ }^{3}$

A avaliação da educação no exterior é uma importante linha de pesquisa, com estudos de longa duração que já nos permitem refletir sobre a dimensão humana da mobilidade, destacando-se o trabalho de Michael Vande Berg e de sua rede de pesquisadores. Segundo Berg, Paige e Lou (2012) existem cinco fatores de impacto, pressupondo-se que o resultado desejável da educação no exterior seja a competência intercultural:

a) imersão cultural: oportunidades para que estudantes e professores se envolvam e engagem na cultura estrangeira (moradia com família local, cursar disciplinas junto com estudantes do país anfitrião, realizar estágios em empresas estrangeiras);

b) reflexão cultural: analisar as experiências culturais de modo estrutural e sistemático (seminários, diários, escrever artigos sobre eventos interculturais);

c) orientação cultural (mentoring): pedagogia intercultural que consiste da orientação, apoio e facilitação do aprendizado e do desenvolvimento

2 Segundo o glossário do "Forum of Education Abroad", um programa de educação no exterior ("Education Abroad Program") é aquele que oferece atividades em sala de aula e/ou extra-classe, incluindo uma experiência no exterior com concessão de créditos ou aproveitamento de estudos (FÓRUM SOBRE EDUCAÇÃO NO EXTERIOR, 2015).

3 Exemplos em evidência tem sido os programas da CAPES em cooperação com agências estrangeiras tais como a Comissão Fulbright (USA) e DAAD (Alemanha), bem como o SANTANDER universidades. 
cultural - on line e presencial; feita por orientador com competência cultural - conhecedor de conceitos culturais, da teoria de desenvolvimento cultural e do continuum de desenvolvimento cultural; utilizar os resultados do IDI para monitorar o grau de desenvolvimento cultural do do aluno ou professor;

d) conteúdo cultural: o conteúdo cultural inclui a definição de cultura; os elementos culturais; conceitos culturais gerais (tais como comunicação não verbal, valores culturais, estilos de comunicação, desenvolvimento intercultural, choque cultural e adaptação cultural); informação cultural específica (as manifestações de características culturais num contexto cultural específico);

e) facilitação/intermediação intercultural geral: significa utilizar múltiplas abordagens para dar suporte ao desenvolvimento de competência cultural, com estratégias de aprendizado cultural, principalmente abrangendo a orientação pre-partida e o acompanhamento no retorno do exterior, os cursos interculturais, a orientação cultural, o estudo de idiomas, o aprendizado intercultural em programas acadêmicos e o "IDI" (assessoria no desenvolvimento do estudos no exterior).

Percebe-se que esses fatores corroboram as boas práticas e constituem indicadores, sugerindo a complexidade dos instrumentos de avaliação da educação internacional, ainda não amostrados de um ponto de vista brasileiro. A referência aqui considerada provém do IDI ou "Inventário de Desenvolvimento Intercultural” apresentado por Berg, Paige e Lou (2012), concebido para amostrar o grau de transformação sociocultutral de participantes em programas de mobilidade, comparando posturas monoculturais e interculturais. A mentalidade monocultural reflete o apego à cultura do país de origem e é caracterizada por três posturas do sujeito em convívio com outras culturas no exterior: a) Negação - a pessoa não percebe ou alcança diferenças culturais; b) Polarização - a pessoa passa a julgar as diferenças; c) Minimização - a pessoa tende a banalizar as diferenças, sem aproveitá-las para quaisquer fins. A mentalidade intercultural reflete a apropriação e a disponibilidade em aplicar conhecimentos proporcionados pela vivência no exterior, sendo caracterizada por uma postura de curiosidade, no sentido de perceber e analisar as diferenças culturais, bem como empenho na adaptação do sujeito, que procura transpor as diferenças e aproveitá-las em benefício de projetos de vida e/ou profissão. A ênfase em diferenças culturais se justifica, porquanto as similaridades mantém o 
sujeito em uma zona de conforto, enquanto o estranhamento deflagra situações de desafio psicossocial e cognitivo.

O IDI (BERG; PAIGE; LOU, 2012) reflete uma coleta de dados substancial, com validade e abrangência por amostra com 10000 indivíduos de procedências culturais e diversidade internacional e, doméstica (respondentes de egressos de mobilidade naturais dos Estados Unidos da América). O instrumento de coleta de dados é um questionário com 50 perguntas. Inclui questões abertas e possibilita agregar até seis questões únicas, havendo aplicativos Educacional e Organizacional costomizados. O IDI é, portanto, um serviço de avaliação por meio de um produto já traduzido em 14 idiomas e utilizado em 30 países, em mais de 170 universidades. ${ }^{4}$ Em dois de seus casos notáveis, a imersão e vivência no exterior não resultam, necessariamente, em competência intercultural: a) em questionários respondidos por 1159 estudantes egressos de 61 programas de mobilidade da Universidade de Georgetown (no ano de 2009, com 138 sujeitos no grupo de controle); b) em amostra de 2.100 estudantes de 6 paises participantes de intercâmbio pela American Field Service (AFS) no ensino médio (em 2002, com 600 sujeitos em grupo de controle).

O IDI amostra o grau de transformação sociocultutral de participantes em programas de mobilidade, comparando posturas monoculturais e interculturais. A mentalidade monocultural reflete o apego à cultura do país de origem e é caracterizada por três posturas do sujeito em convívio com outras culturas no exterior: a) Negação - a pessoa não percebe ou alcança diferenças culturais; b) Polarização - a pessoa passa a julgar as diferenças; c) Minimização - a pessoa tende a banalizar as diferenças, sem aproveitá-las para quaisquer fins. A Mentalidade intercultural reflete a apropriação e a disponibilidade em aplicar conhecimentos interculturais. É caracterizada por uma postura de curiosidade no sentido de perceber e analisar as diferenças culturais, bem como empenho na adaptação do sujeito, que procura transpor as diferenças culturais e aproveitá-las em benefício de projetos de vida e/ou profissão.

Os estudos resenhados sugerem que a vivência no exterior não assegura a competência intercultural. Além disso, o aprendizado de uma língua estrangeira e o bom desempenho em disciplinas cursadas no exterior não são os principais indicadores de competência intercultural. Outros resultados da mobilidade, os quais não se podem pode medir em termos de quantidade de produtos e patentes, são o envolvimento com questões globais e a disponibilidade para interagir e intervir socialmente. Existem, portanto, diferentes argumentos e narrativas

4 Um site na Internet disponibiliza amplas informações: www.idiinventory.com . Úlitimo acesso aos 16/06/2013. 
para a validação dos milhões de dólares destinados à educação internacional. Aponta-se o positivismo, o relativismo e o construtivismo como as três principais narrativas em competição, com um alerta: "A força social de uma narrativa nos leva a perceber seletivamente os fatos coerentes com os seus pressupostos e a ignorar, negar, minimizar, e a explicar de outro modo, tudo o que nela não se enquadra" (BERG; PAIGE; LOU, 2012, p. 15).

Embora a narrativa positivista, que reforça o aprendizado por meio do contato com o novo e o diferente, tenha predominado durante o século $\mathrm{XX}$, Berg, Paige e Lou (2012) ainda percebem a sua força no referencial de programas internacionais atuais. Do mesmo modo, nota-se a recorrência do paradigma relativista, o qual enfatiza a estratégia de imersão no ambiente novo e diferente para assimilar os seus aspectos universais e, assim, transcender as diferenças. O paradigma construtivista ganhou adeptos na última década e enfatiza o papel de mediadores capacitados na experiência de mobilidade, facilitando o ensino e o aprendizado por meio de estratégias apropriadas e um plano intencional de intervenção. No Brasil, o programa Ciência Sem Fronteiras ilustra um misto das narrativas positivista e relativista, sendo possível que um estudante cumpra o seu contrato sem haver nenhuma intervenção na instituição de origem. Ou seja, apesar de proporcionar os recursos financeiros para a mobilidade, o programa não contempla, em nível de graduação, o desenvolvimento de parcerias acadêmicas voltadas para a continuidade, a disseminação e a aplicação do aprendizado, embora o bolsista deva cumprir um contrato de retorno ao Brasil.

Por outro lado, o programa UNIBRAL, também apoiado pela CAPES, é concebido do ponto de vista construtivista, proporcionando o constante acompanhamento e o real intercâmbio, com a previsão de acolhimento de estudantes internacionais da Alemanha no Brasil, apoiados pelo DAAD. Com isso, criam-se as condições para um trabalho processual de internacionalização, conforme verificamos nos resultados da experiência do Curso de Engenharia Florestal da UNICENTRO, em sua cooperação com a Universidade de Rottenburg, da Alemanha.

\section{O caso de internacionalização do curso de engenharia florestal da Unicentro}

Uma retrospectiva e avaliação da experiência de internacionalização do curso de Engenharia Florestal da UNICENTRO requer, primeiramente, a apreciação de sua dinâmica ao longo de seis anos, com a busca de alternativas de financia- 
mento. O projeto da UNICENTRO ao programa UNIBRAL-CAPES-DAAD teve sua origem no ano de 2008 quando, em uma iniciativa governamental da Secretaria da Ciência, Tecnologia e Ensino Superior do Estado do Paraná, buscou-se a aproximação entre as nossas universidades e as universidades do estado de Baden-Württemberg, Alemanha, a partir de uma visita de uma delegação às instituições.

Como resultado dessa incursão governamental, o estado do Paraná recebeu a visita, em 2009, de um professor da Universidade de Rottenburg, que se interessou por uma parceria com o curso de Engenhariai Florestal da UNICENTRO. Logo em seguida a esta visita, professores da UNICENTRO retribuíram, visitando Rottenburg e iniciando as tratativas para um convênio, visando a elaboração de projetos bilaterais no programa UNIBRAL, parceria entre CAPES e DAAD.

Nessa ocasião, os currículos dos cursos de graduação em Engenharia Florestal de cada instituição foram estudados e as prováveis equivalências e estratégias da mobilidade foram traçadas. Um projeto de pesquisa e desenvolvimento visando a definição de estratégias de manejo florestal em pequenas propriedades rurais para a região Centro-Sul do Paraná também foi discutido. Ambos os projetos foram elaborados e encaminhados ainda em 2009. O projeto UNIBRAL não foi aprovado pela CAPES/DAAD naquele ano, mas o projeto de manejo foi aprovado por ambos os estados com recursos da ordem de 1,1 milhão de reais, 75 e 25\%, respectivamente, advindos dos estados do Paraná e de Baden-Württemberg. O projeto de manejo florestal em 36 pequenas propriedades rurais na região de Irati está em franco desenvolvimento e teve sua prorrogação aprovada pelos dois estados para o biênio 2013-2015, com recursos adicionais da ordem de dois milhões de reais. O projeto tem tido grande repercussão na região e no estado do Paraná, com frequentes visitas externas, cabendo destacar que envolve a coordenação de dois professores (Brasileiro e Alemão), dois gerentes técnicos (Brasileiro e Alemão), sete bolsistas recém-formados, seis bolsistas acadêmicos e a participação de vários professores da UNICENTRO, pesquisadores da EMBRAPA Florestas e técnicos dos órgãos estaduais ligados ao meio ambiente: EMATER, IAP, SEAB e SEMA.

A implantação do projeto de manejo em pequenas propriedades, formalizando a cooperação entre a UNICENTRO e a Univerisdade de Rottenburg, foi fundamental na avaliação binacional de nova tentativa do projeto UNIBRAL em 2010, recebendo a aprovação da CAPES e DAAD para o biênio 2011-2012. $\mathrm{Na}$ primeira fase do programa, 9 estudantes da engenharia florestal da UNI- 
CENTRO estiveram estudando na Universidade de Rottenburg por 11 meses, enquanto 4 estudantes alemães estudaram no campus de Irati, com permanência de 6 a 11 meses.

Um dos aspectos mais positivos na aproximação entre as duas universidades é proporcionado no programa UNIBRAL, o qual prevê, além do intercâmbio entre estudantes de graduação, a mobilidade de professores em missões de trabalho que podem transcorrer em um período de 10 a 20 dias. No primeiro biênio, tivemos 4 missões, envolvendo 8 professores (4 de cada instituição) em visitas recíprocas. Essas missões, além de avaliar permanentemente o intercâmbio dos estudantes, buscando constantes melhorias, tem um componente da mais alta relevância porque, durante a permanência na universidade receptora, os docentes pesquisadores realizam palestras técnicas sobre a prática florestal em seus países. Além disso, cumpre-se uma agenda bastante intensa de visitas técnicas às florestas da região, empresas, indústrias, cooperativas florestais e órgãos de pesquisa. Essas missões têm sido fundamentais para que os professores conheçam de perto as realidades do setor florestal e vivenciem os aspectos culturais de cada país.

Nessas missões, surgem novos embriões de atividades/projetos que podem ser iniciadas entre as duas universidades. Das últimas missões de trabalho, por exemplo, surgiu a possibilidade de uma cooperação na área de energia de biomassa, um campo estratégico para o Brasil, no qual os professores de Rottenburg detêm grande experiência e inclusive um programa de mestrado. Dois professores visitaram a UNICENTRO em fevereiro de 2012, para conhecer o nosso contexto e intensificar as tratativas da nova parceria. A idéia inicial foi a de criação de uma linha de pesquisa em "Bioenergia de Biomassa florestal" no curso de mestrado em Ciências Florestais da UNICENTRO no campus de Irati. Um projeto inicial de curso de especialização sobre o tema já está sendo estruturado, prevendo que professores de Rottenburg venham ministrar cursos e orientar/coorientar alunos da pós-graduação. Outro projeto, nessa linha, foi aprovado pela Fundação Araucária no mês de junho 2013, proporcionando a ida de alunos do mestrado para fazer cursos no mestrado em bioenergia de biomassa de Rottenburg, além da possibilidade de desenvolver suas pesquisas em laboratórios, recebendo coorientação de professores da instituição parceira.

Em dezembro de 2012, a CAPES e DAAD aprovaram a prorrogação do projeto UNIBRAL da Engenharia Florestal Unicentro para o biênio 2013-2014. Como isso, viabilizaremos o intercâmbio de 14 estudantes da UNICENTRO, que irão por 11 meses para Rottenburg. De outro lado, a UNICENTRO rece- 
berá 8 estudantes de Rottenburg que permanecerão em Irati por 6 a 11 meses. Também 8 professores das duas universidades estarão em visitas recíprocas nas missões de trabalho, além de mais 4 professores da UNICENTRO que irão para a Alemanha pelo novo projeto do Mestrado, aprovado pela Fundação Araucária. É importante ressaltar que essas duas fases do projeto UNIBRAL envolvem recursos da ordem de 850 milhões de reais, apenas para a parte brasileira. Esses recursos são de responsabilidade da CAPES. Do lado da Alemanha, o DAAD disponibiliza os recursos e financia as bolsas aos estudantes (870 euros/mês), passagens aéreas, auxílio moradia, seguro saúde e diárias para as missões de trabalho.

Além dos resultados já comentados, pertinentes à mobilidade internacional e à cooperação nos programas de graduação em Engenharia Florestal e mestrado em Ciências Florestais, várias outras ações foram desenvolvidas nesse período de dois anos e meio da efetiva aproximação UNICENTRO-Universidade de Rottenburg, valendo destacar as seguintes:

a) Oferta no Campus de Irati de cursos de Alemão para os alunos do Campus e também da comunidade; Oferta de Português para os estudantes da Alemanha;

a) Organização de seminário internacional (31.03 a 01.04.2011) em parceria com EMBRAPA Florestas: "Workshop sobre perspectivas para o Manejo Florestal Sustentável (MFS) em pequenas propriedades no sul do Brasil”, com palestras de professores da UNICENTRO e de Rottenburg, além de uma discussão intensa a respeito do projeto de manejo florestal já em andamento à época; o Seminário contou ainda com a participação de professores de três universidades da Alemanha, uma universidade da Espanha, UFPR e técnicos da EMATER, IAP, IBAMA;

b) Publicação de capítulo de livro internacional em parceria com a EMBRAPA Florestas: http://www.intechopen.com/books/sustainable-forest-management-case-studies/sustainable-forest-management-in-rural-southern-brazil-exploring-participatory-forest-management-pla;

c) Realização de quatro colóquios internacionais Brasil-Alemanha.

É importante ressaltar que a UNICENTRO é uma universidade jovem, fundada em 1990, dando os seus primeiros passos em direção à sua internacionalização. Como todas as instituições emergentes no interior do Brasil 
após a ditadura, tem um papel crucial na verticalização do ensino superior e na melhoria do acesso ao mesmo. A região de abrangência da UNICENTRO compreende cerca de 50 municípios e mais de um milhão de habitantes, nas mesorregiões sudeste e centro-sul do estado do Paraná (PARANÁ, 2012), com indicadores socioeconômicos comparados às regiões mais pobres do Brasil. $\mathrm{O}$ impacto da universidade se verifica na transformação socioeconômica dessas mesorregiões, atuando na geração de emprego e renda, no desenvolvimento tecnológico, cultural e científico, ganhando uma dimensão ainda maior com a internacionalização institucional, projetos bilaterais de cooperação e a perspectiva de carreiras cosmopolitas.

O programa UNIBRAL entre os dois cursos de Engenharia Florestal das duas universidades foi o primeiro intercâmbio internacional com relevância para a internacionalização sistemática da UNICENTRO. Face às diversas ações realizadas, desde 2008, parecem óbvios os benefícios gerados e a sua importância não apenas para a comunidade da Universidade, mas da região, podendo alcançar uma abrangência muito maior e transcender o estado e o país. O sucesso dessa parceria está diretamente ligado às pessoas envolvidas nas duas instituições e o apoio integral dos administradores das duas Universidades. A rede de cooperação bilateral estabelecida ganhou uma dimensão notável com o projeto de pesquisa e desenvolvimento amparado pelo Estado do Paraná e pela Secretaria da Ciência, Tecnologia e Ensino Superior. Ao mesmo tempo que o período de seis anos parece curto, quando pensamos na avaliação institucional ou, especificamente, na avaliação de programas de pós-graduação, é importante observar que implica o trabalho sistematico durante dois triênios. A criação de condições adequadas para a internacionalização de uma sub-área de conhecimento, portanto, não acontece com imediatismos. É um processo lento, cujo sucesso está diretamente relacionado a um aporte financeiro adequado para as ações.

Dados os cinco principais fatores de impacto da educação internacional, apontados por Berg, Paige e Lou (2012), percebe-se que, em seu atual estágio, a internacionalização do curso de Engenharia Florestal da Unicentro em cooperação com a Universidade de Rottenburg, na Alemanha, tem sido consistente com uma abordagem construtivista e proporcionou, aos docentes e estudantes, oportunidade de imersão, reflexão, conteúdo, orientação e facilitação culturais, com impacto objetivo na produção e na disseminação de conhecimento, no aperfeiçoamento profissional dos corpos discente e docente, e aplicação em pequenas propriedades localizadas no município de Irati mesorregião sudeste do estado do Paraná (PARANÁ, 2012). 


\section{Considerações finais}

Os três pilares da universidade brasileira são o ensino, a pesquisa e a extensão. Essa estrutura vem da universidade alemã de Humboldt, mas se diferencia do modelo do MIT, dos Estados Unidos, calcado na inovação como principal indicador de qualidade da educação superior. O modelo de inovação teve forte influência nos países asiáticos, como se percebe no KAIST, conhecido como o MIT coreano. Mesmo no âmbito do BRICS, portanto, existem profundas diferenças nas concepções da universidade e seu propósito. Além disso, o sistema de formação nos liberal arts colleges como pre-requisito para a entrada nas universidades nos Estados Unidos, conforme o pensamento de Abraham Flexner, mentor de reforma na área da saúde nas décadas iniciais do século XX (SANTOS et al., 2013), não vem ao encontro de diretrizes brasileiras.

A alternativa construtivista é coerente com a mentalidade de nucleação inerente aos nossos programas de iniciação científica e de pós-graduação, embora não haja uma política de valorização de nossos notáveis e nem de engajamento de nossos egressos da mobilidade internacional, para os quais o "brain drain" tende a tornar-se uma atraente opção. A mera inserção de corpos nos programas de mobilidade internacional, sem nenhum plano de intervenção e atenção à linhas de pesquisa, reforça apenas uma dinâmica de concessão de bolsas, sem perspectiva de retorno social. O maior impacto da educação internacional parece estar nas performances interculturais que ela pode gerar, sobretudo para a construção de redes de cooperação. O desafio é transversal e complexo, muito além do que a satisfação de bolsistas egressos de programas de mobilidade possa contribuir para a melhoria da nota de seus cursos no Enade. Os aspectos do aprendizado decorrente de estudos no exterior e o desenvolvimento de estudantes está atrelado não só a objetivos de projetos pedagógicos e curriculares, mas a processos de revisão internos e externos, cuja implementação é lenta e requer instrumentos de avaliação adequados para a diversidade social em nosso país.

As experiências no Programa UNIBRAL, na UNICENTRO, reafirmam os benefícios e impactos globais decorrentes da mobilidade internacional. O estudo de caso descrito evidencia que as ações excederam, em muito, o intercâmbio de estudantes de graduação porque, em um curto espaço de tempo, a aproximação ganhou dimensões muito maiores. Além de observando-se o entusiasmo nos alunos selecionados para participar do programa ou, quando retornavam, as muitas proezas compartilhadas, concretamente, já houve o envolvimento de alunos egressos do UNIBRAL em nível de pós-graduação, realizando disciplinas e partes de suas dissertações na Alemanha. Jovens doutores professores 
também vislumbram a possibilidade de virem a fazer um pós-doutorado como fruto da parceria, assim como articulou-se se a possibilidade de trazer a experiência alemã na formação de nossos mestres e futuros doutores. Um futuro muito promissor ainda é esperado dessa parceria entre as duas universidades e isto não é um otimismo desprovido de parâmetros, mas baseado na seriedade e confiança das pessoas envolvidas em ambos os lados. Isso nos parece fundamental para o sucesso de qualquer cooperação, sobretudo internacional. Há um acentuado interesse no crescimento da parceria por parte dos professores/ administradores brasileiros e alemães das duas universidades.

O termo "educação internacional" tem suscitado discussões relacionadas ao seu próprio sentido. Como a educação internacional difere daquela sem teor internacional? O conhecimento, em si, já abrange as contribuições de diferentes povos. O que se pretende, então, com o termo educação internacional? Em nossa percepção, a educação internacional é aquela que propõe o pensar sistemático sobre os desmembramentos globais da intervenção das pessoas sobre a sociedade, por meio de currículos nos quais se articulam as perspectivas inter e transculturais, abrangendo o contato com idiomas estrangeiros e redes de cooperação. No processo de internacionalizaçãoda educação superior no Brasil, as diferentes abordagens positivista, relativista e construtivista têm um impacto nas políticas dos programas e, consequentemente, nos resultados da mobilidade discente e docente. Se pretendemos aprofundar quaisquer reflexões sobre resultados emancipatórios, carecemos de uma metodologia eficaz, contemplando a dimensão global e intercultural da mobilidade internacional na educação superior, analisando a sua integração e/ou disjunção, intensificando o relacionamento entre sistemas, comportamentos e estilos. Construir instrumentos de avaliação de desempenho dos nossos egressos, a fim de analisar a aplicabilidade social de sua educação internacional, permance uma tarefa cujo desenrolar é urgente na área de Educação.

\section{Referências}

BERG, Michael Vande; PAIGE, Michael, LOU, Kris Hemming. Student learning abroad: What our students are learning, what they are not, and what they can do about it. Sterling, VA: Styllus, 2012.

BOAL, Augusto. Teatro do oprimido e outras poéticas políticas. Rio de Janeiro: Civilização Brasileira, 1975. 
BOAL, Augusto. Teatro legislativo: versão beta. Rio de Janeiro: Civilização Brasileira, 1996.

COHEN-CRUZ, Jan (Editor). Radical street performance: an international anthology. London: Routledge, 1998.

DIAS SOBRINHO, José. Educação superior: bem público, equidade e democratização. Avaliação, Campinas; Sorocaba, SP, v. 18, n. 1, p. 107-126, mar. 2013.

FÓRUM SOBRE EDUCAÇÃO NO EXTERIOR. Padrões de Boas Práticas da Educação no Exterior [Standards of Good Practice for Education Abroad]. 2015. Manual disponível em: < https://forumea.org/2015/03/18/ standards-5th-ed/ $\geq$. Acesso em: 27/08/2016.

GUATTARI, Félix. Caosmose: um novo paradigma estético. São Paulo: Editora 34, 2012.

LIMA, Licínio C.; AZEVEDO, Mário Luiz Neves de; CATANI, Afrânio Mendes. O Processo de Bolonha, a avaliação da educação superior e algumas considerações sobre a Universidade Nova. Avaliação, Campinas; Sorocaba, SP, v. 13, n.1, p 7-36, mar. 2008.

MORIN, Edgar. Saberes globais e saberes locais: o olhar transdisciplinar/ participação de Marcos Terena. Rio de Janeiro: Garamond, 2010.

PÄLL, Allan. Death of the Degree. In: RUMBLEY, Laura E. Rethinking Education. Reshaping Economies. Amsterdam: European Association for International Education, 2012. p. 27-30.

PARANÁ. Relação dos municípios do Estado ordenados segundo as mesorregiões e as microrregiões geográficas do IBGE. Paraná: Instituto Paranaense de Desenvolvimento Econômico (IPARDES), 2012. Disponível em: <http://www.ipardes.gov.br/pdf/mapas/base_fisica/relacao_mun micros_mesos_parana.pdf>.Acesso em: 16/06/2013.

POMPEU, Renato. Dialética da feijoada. São Paulo: Vértice, 1986.

SANTOS, Fernando Seabra; NASCIMENTO, Elimar Pinheiro do; BUARQUE, Cristovam. Mudanças necessárias na universidade brasileira: autonomia, forma de governo e internacionalização. Educação em Revista, Belo Horizonte, v. 29, n. 1, p. 39-61, mar. 2013. 
SCHECHNER, Richard. Performance studies. An introduction. London; New York: Routledge, 2002.

SODRÉ, Muniz. A verdade seduzida. Por um conceito de cultura no Brasil. 3. ed. Rio de Janeiro: DP\&A, 2005.

Margarida Gandara Rauen - Universidade Estadual do Centro-Oeste Guarapuava | PR | Brasil. Contato: margierauen.br@gmail.com

Afonso Figueiredo Filho - Universidade Federal do Paraná Curitiba | PR | Brasil. Contato: afigfilho@gmail.com

Artigo recebido em 6 de agosto de 2013 e aprovado em 29 de maio de 2016. 